\title{
Influence of Surgical Technique on Overall Survival, Disease Free Interval and New Lesion Development Interval in Dogs with Mammary Tumors
}

\author{
Rodrigo dos Santos Horta ${ }^{*}$, Gleidice Eunice Lavalle ${ }^{1}$, Rúbia Monteiro de Castro Cunha ${ }^{1}$, \\ Larissa Layara de Moura1, Roberto Baracat de Araújo1, Geovanni Dantas Cassali2 \\ ${ }^{1}$ Veterinary School, Universidade Federal de Minas Gerais-UFMG, Belo Horizonte, Brazil \\ ${ }^{2}$ Biological Sciences Institute, Universidade Federal de Minas Gerais-UFMG, Belo Horizonte, Brazil \\ Email: ${ }^{*}$ rodrigohvet@gmail.com
}

Received 10 March 2014; revised 4 April 2014; accepted 11 April 2014

Copyright (C) 2014 by authors and Scientific Research Publishing Inc.

This work is licensed under the Creative Commons Attribution International License (CC BY).

http://creativecommons.org/licenses/by/4.0/

(c) (i) Open Access

\begin{abstract}
The best surgical technique for the treatment of mammary tumors in female dogs has been exhaustively debated among the scientific community. Despite biological knowledge of these tumors, some authors have suggested aggressive procedures, without any clinical advantage. The aim of this study was to evaluate the influence of surgical procedure on the overall survival, disease-free interval and new lesion development interval in dogs with mammary tumors treated according to established prognostic factors. This prospective study included 143 intact female dogs that underwent surgery for mammary neoplasms and were followed up for about 738.5 days. Each animal represented a repetition. Each surgical technique represented a group: lumpectomy (P1), mammectomy (P2), regional mastectomy without cranial abdominal gland involvement (P3), regional mastectomy with cranial abdominal gland involvement (P4), and radical mastectomy (P5). Considering only the first surgical event, $84.6 \%$ of animals had more than one mammary tumor, and tumors were identified in two mammary chains in $\mathbf{5 2 . 5 \%}$. There was no difference in ipsilateral and contralateral tumor development when surgical techniques were compared. Only 33 dogs developed new lesions in remaining mammary tissue, without correlation with primary lesion. Surgical technique had no effect on the overall survival, diseasefree interval and new lesion development interval in patients on this study, which respected oncological surgery principles and established prognostic factors for mammary gland tumors in dogs.
\end{abstract}

\footnotetext{
${ }^{*}$ Corresponding author.
}

How to cite this paper: Horta, R.S., et al. (2014) Influence of Surgical Technique on Overall Survival, Disease Free Interval and New Lesion Development Interval in Dogs with Mammary Tumors. Advances in Breast Cancer Research, 3, 38-46. 


\section{Keywords}

\section{Female Dog, Mammary Neoplasms, Mastectomy}

\section{Introduction}

Mammary gland tumors represent $42 \%$ of all tumors in the female dog [1]. Although there are numerous studies about disease development and progression, some questions concerning the surgical treatment remain unanswered [2].

Similar to human mammary neoplams [3], lymphatic system represents the main route of metastasis of mammary malignant pathologies of dogs and cats [4]-[6]. In the dog, cranial and caudal thoracic glands drain to axillary lymph nodes, whilst inguinal and caudal abdominal glands drain to inguinal lymph nodes. Cranial abdominal gland, however, may drain to either axillary or inguinal lymph nodes [4] [7]. Axillary lymph nodes are rarely related to mammary cancer in the dog and must be removed with caution, in selected cases. The inguinal lymph node, which is intimately associated with the ipsilateral inguinal gland, should be removed whenever this gland is surgically removed [5]. Connections between glands on different sides and between other mammary glands are rare, but may exist [7]. Pereira et al. (2003) [8] reported that neoplastic lesions may induce the development of lymphatic anastomoses, modifying the natural drainage of mammary tissue.

Surgery is the basic treatment of canine mammary tumors and is the most effective for disease regional control [4]. Many surgical techniques may be used for the treatment of canine mammary tumors [5] [9] and similar to Medicine [10] [11]. The advantages and disadvantages of each procedure have been extensively discussed [12]. Radical surgeries were thoroughly performed on women with mammary tumors between 1910 and 1964, without any clinical benefits [13] [14]. As from the 1950's, Halsted's mastectomy started to be questioned [11], however, the lack of clinical benefits of the radical mastectomy was only proved by the end of the 1970's [10]. When studying the biological behavior of canine mammary tumors, Gilbertson et al. (1983) [15] indicated the radical mastectomy as the best surgical option. In the same year, Brodey et al. (1983) [16] advocated individual treatments, in which surgical procedure should respect known lymphatic connections and base itself on tumor location, number and size of lesions and existence of skin or muscular adherences. Similar to Medicine, a prospective study conducted by MacEwen et al. (1985) [17], with 144 dogs, did not find any difference between the recurrence rate and the survival time when the single mastectomy was compared to chain mastectomy.

A greater understanding about the canine mammary pathology and new therapeutic modalities made the definition of distinct groups regarding prognosis and treatment possible [6]. Aggressive surgical procedures for the treatment of localized lesions may reduce the risk of developing new lesions in a small number of dogs, especially in young intact bitches [5]. Stratmann et al. (2008) [2] also indicated radical mastectomy as the best surgical option, regardless of the number and the size of lesions. Authors reported a greater probability of new tumor growth ipsilateral to the first surgery, although statistical significance was not assessed.

The purpose of this study is to evaluate the influence of surgical procedure on the survival time, disease free interval and new lesion development interval in dogs with mammary tumors treated according to the biological behavior of these lesions.

\section{Materials and Methods}

\subsection{Inclusion Criteria}

Intact bitches were submitted to surgery for the treatment of mammary tumors. Patients that had malignancies with compromised surgical margins (accessed by histopathological evaluation) and/or dogs submitted to targeted adjuvant therapies with the usage of cyclooxygenase inhibitors or ovariohisterectomy during the follow-up were excluded. Adjuvant chemotherapy was performed in selected patients. Candidates to chemotherapy were those with lymph node or distant metastasis and patients with guarded to poor prognostic tumor diagnoses including: micropapilar carcinoma, high degree tubular carcinoma, mucinous, secretory or lipid-rich carcinoma, solid carcinoma, malignant myoepithelioma, carcinosarcoma and other sarcomas [6].

Prior to surgery, all animals went through a complete clinical exam, abdominal ultrasound and two-view tho- 
racic radiographs were taken for metastasis evaluation. Lymph nodes with size, shape or consistency alterations were removed during surgery, but were primarily submitted to fine-needle aspiration cytology for metastasis evaluation.

The ethics committee on animal experiments approved this study (023/2011).

\subsection{Choosing the Surgical Technique}

The removal of mammary tumors was performed through the simplest and less invasive surgical procedure necessary to the complete removal of all tumors and main known lymphatic connections between affected glands, as suggested by Brodey et al. (1983) [16] and Sorenmo et al. (2013) [5].

It was not possible to separate the surgical technique used from the type and stage of disease, once the surgical technique was chosen according to number of lesions and site, respecting lymphatic drainage and established prognostic factors such as lesions size and existence of skin or muscular adherences.

Lumpectomy was considered for the removal of single solid superficial non-adherent tumors less than two centimeter wide. Lesions larger than two centimeters implied the need to remove the entire gland. Mammectomy or simple mastectomy was indicated for lesions up to three centimeters, affecting only one gland whilst regional mastectomy was indicated for the removal of lymphatic connections of glands affected by lesions larger than three centimeters. The removal of cranial abdominal gland during regional mastectomy was sometimes necessary to obtain adequate surgical margins or for lesions between one and three centimeters in this gland. Radical mastectomy was the removal of a unilateral mammary chain, when lesions larger than three centimeters affected the cranial abdominal gland. Regional and radical mastectomies were also performed on multiple lesions, of one to three centimeters, to obtain a single surgical wound through a single incision and resection of mammary tissue.

The inguinal lymph nodes were resected in bloc with the inguinal mammary gland whenever this gland was removed or, by the same way as axillary lymph nodes, when changes in their shape, volume or consistency were observed.

The surgically removed tumors were submitted to surgical margin analyses, histopathological evaluation and classification, as proposed by Cassali et al. (2011) [6].

\subsection{Clinical Follow-Up}

Throughout clinical follow up, dogs were examined, including abdominal ultrasound and thoracic radiographic exams, in intervals from three to six months or sooner, in case the owner recognized changes on the mammary chain or in case the patient was submitted to adjuvant chemotherapy. Subsequent surgery was indicated and performed in dogs that developed recurrences or new tumors on the remaining mammary tissue.

The survival time was defined as the time (in days) from the first surgery until death related to the disease. Disease free interval was defined as the time (in months) from the first surgery until development of local recurrence or distant metastatic disease. New mammary lesion development interval was defined as time (in months) from the first surgery until development of subsequent lesions in the remaining mammary tissue.

\subsection{Experimental Design and Statistical Analysis}

Each animal represented a repetition. Each surgical technique represented a group: lumpectomy (P1), mammectomy (P2), regional mastectomy without cranial abdominal gland involvement (P3), regional mastectomy with cranial abdominal gland involvement (P4), and radical mastectomy (P5).

After the descriptive analysis of data and the determination of malignant lesion frequency according to the surgical technique, the groups were compared with chi-squared test.

The Spearmann's test was used to determine the correlation between the number of lesions and the number of histological diagnoses in dogs that presented multiple mammary lesions at initial diagnoses or that underwent new surgical procedures, due to the development of new lesions in the remaining mammary tissue.

The Spearman's correlation was used to access the association between surgical technique and patient staging. The ages of animals in each surgical technique group were submitted to analysis of variance and the median values were compared with Fisher exact test and Tukey's post-test.

New tumor development can only happen on the same gland of dogs treated by lumpectomy. Radical mas- 
tectomy precludes new ipsilateral tumor development. Therefore, new contralateral and ipsilateral mammary lesion development in each surgical technique (with the exception of ipsilateral lesions frequency evaluation for radical mastectomy) was compared by the usage of a chi-squared analysis.

The overall survival, disease free interval and new mammary lesion development interval (unrelated to primary tumor) were estimated by Kaplan-Meier product limit method. The Longrank statistics of Cox-Mantel was used to compare groups. Some cases were censored for analysis whenever follow-up was lost or death was not related to the disease.

Statistical significance for all testing procedures was set at $5 \%$.

\section{Results}

143 patients were included in this study. Adjuvant chemotherapy was performed with carboplatin $(n=23)$, carboplatin and doxorubicin $(n=6)$ or gencitabin and carboplatin $(n=2)$. Median follow-up was of 738.5 days. The dogs ages ranged from three to 16 years (mean $9.2 \pm 2.3$ years). There were 23 mixed breed dogs (16\%) with the other 120 dogs representing 25 breeds. Poodle was the most common breed $(n=52 ; 36.4 \%)$, followed by Cocker Spaniel $(n=11 ; 7.7 \%)$ and Yorkshire terrier $(n=10 ; 7 \%)$ (Table 1$)$.

Considering only the first surgical procedure, 121 (84.6\%) of 143 dogs had more than one mammary lesion, and $52.5 \%$ of animals had tumors on both mammary chains. Histopathological diagnosis were established for 391 lesions, and 219 (56\%) were classified as malignant neoplasms, 121 (31\%) were benign neoplasms and 49 (12.5\%) were non-neoplastic lesions. Histological types, in each surgical technique, are demonstrated on Table 2. Benign mixed tumor represented $56.2 \%$ of benign neoplasms, followed by papilloma (23.1\%) and adenomas (17.4\%). Carcinoma in mixed tumor was the most frequent mammary cancer (47.5\%), followed by malignant lesions "in situ" (23.3\%) and papillary carcinoma (7.7\%).

There were no significant differences between surgical techniques with regard to malignant lesion frequency $(\mathrm{p}>0.05)$, however, there was a correlation between patient staging and surgical technique $(\mathrm{p}<0.0001$; $\mathrm{rs}=$ $0.409)$ and between staging and patient age $(\mathrm{p}<0.002$; $\mathrm{rs}=0.247)$. The number of animals submitted to each technique and mean age in each group are demonstrated on Table 3. Dogs submitted to lumpectomy (P1) were younger than dogs on other groups, and so were animals submitted to regional mastectomy without removal of cranial abdominal gland (P3) compared with those submitted to radical mastectomy (P5) (p < 0.0001).

There was no significant correlation between lesions, but there was a strong association between number of mammary tumors and histological diagnoses variety ( $<0.0001$; $\mathrm{rs}=0.833$ ), as shown on Table 4 . Thirty-three (24.8\%) dogs developed new tumors on the remaining mammary tissue. The number and percentage of animals that developed new tumors on the same gland where the first tumor was removed (only for lumpectomies), the ipsilateral chain adjacent mammary gland or not adjacent (except for radical mastectomy) or the contralateral mammary chain, according to surgical technique, is shown on Table 5. New lesions were not observed in $30 \%$, 72.7\%, 72.7\%, 71.4\% and 90.2\% of dogs in groups P1, P2, P3, P4 and P5, respectively. There was no significant

Table 1. Breeds from the 143 dogs submitted to surgical treatment for the removal of mammary tumors.

\begin{tabular}{ccc} 
& Number & Percentage \\
\hline Poodle & 52 & $36.4 \%$ \\
Cocker Spaniel & 11 & $7.7 \%$ \\
Yorkshire Terrier & 10 & $7.0 \%$ \\
Dachshund & 7 & $4.9 \%$ \\
Pinscher & 6 & $4.2 \%$ \\
German Shepherd & 6 & $4.2 \%$ \\
Bichon frise & 4 & $2.8 \%$ \\
Others & 24 & $16.8 \%$ \\
Crossbreed & 23 & $16.1 \%$ \\
Total & 143 & $100 \%$ \\
\hline
\end{tabular}


Table 2. Histopathological exams results and number of lesions found for each tumor type for each surgical technique on 143 dogs.

\begin{tabular}{|c|c|c|c|c|c|c|}
\hline \multirow[b]{2}{*}{ Malignant neoplasms } & \multicolumn{6}{|c|}{ Surgical technique } \\
\hline & $\mathrm{P} 1$ & P2 & P3 & $\mathrm{P} 4$ & P5 & TOTAL \\
\hline Carcinoma in mixed tumor & 6 & 5 & 25 & 12 & 56 & 104 \\
\hline "in situ” carcinoma & 1 & 2 & 6 & 13 & 29 & 51 \\
\hline Papillary carcinoma & 0 & 1 & 2 & 4 & 10 & 17 \\
\hline Tubular carcinoma & 0 & 0 & 0 & 1 & 10 & 11 \\
\hline Solid carcinoma & 0 & 0 & 0 & 5 & 4 & 9 \\
\hline Tubulopapillary carcinoma & 1 & 0 & 4 & 0 & 3 & 8 \\
\hline Carcinosarcoma & 0 & 0 & 1 & 1 & 4 & 6 \\
\hline Complex carcinoma & 0 & 0 & 2 & 1 & 0 & 3 \\
\hline Mucinous, secretory or lipid-rich carcinoma & 0 & 0 & 0 & 0 & 3 & 3 \\
\hline Malignant myoepithelioma & 0 & 0 & 0 & 0 & 2 & 2 \\
\hline Hemangiosarcoma & 0 & 1 & 1 & 0 & 0 & 2 \\
\hline Sarcoma in mixed tumor & 0 & 0 & 0 & 0 & 1 & 1 \\
\hline Osteosarcoma & 0 & 0 & 0 & 0 & 1 & 1 \\
\hline Micropapillary carcinoma & 0 & 0 & 0 & 0 & 1 & 1 \\
\hline TOTAL & 8 & 9 & 41 & 37 & 124 & 219 \\
\hline \multicolumn{7}{|l|}{ Malignant neoplasms } \\
\hline Benign mixed tumor & 3 & 4 & 16 & 19 & 26 & 68 \\
\hline Papilloma & 1 & 5 & 5 & 5 & 12 & 28 \\
\hline Simple, basaloid and complex adenoma & 0 & 2 & 2 & 6 & 11 & 21 \\
\hline Adenomioepitelioma & 0 & 0 & 1 & 0 & 0 & 1 \\
\hline Lipoma & 0 & 0 & 1 & 0 & 0 & 1 \\
\hline Hemangioma & 0 & 0 & 0 & 0 & 1 & 1 \\
\hline Fibroadenoma & 0 & 0 & 0 & 0 & 1 & 1 \\
\hline TOTAL & 4 & 11 & 25 & 30 & 51 & 121 \\
\hline \multicolumn{7}{|l|}{ Malignant neoplasms } \\
\hline Ductaland lobular hyperplasia & 1 & 0 & 7 & 5 & 19 & 32 \\
\hline Mastitis & 0 & 0 & 2 & 6 & 7 & 15 \\
\hline Columnar cell lesion & 0 & 0 & 0 & 0 & 2 & 2 \\
\hline TOTAL & 1 & 0 & 9 & 11 & 28 & 49 \\
\hline
\end{tabular}

P1—Lumpectomy; P2-Mammectomy; P3—Regional mastectomy without involvement of cranial abdominal gland; P4—Regional mastectomy with involvement of cranial abdominal gland; P5—Radical mastectomy.

difference between development of tumors ipsilaterally or contralaterally in regard to surgical technique ( $\mathrm{p}>$ $0.05)$.

During follow-up, only fifteen, of 33 animals that developed new mammary lesions on the remaining tissue after the first surgery were submitted to subsequent surgery. There was no correlation between lesions $(p>0.05)$, and only five dogs (33.3\%) had the same histological type on both procedures. 
Table 3. Number of animals, mean of age and standard deviation in each group, by surgical technique.

\begin{tabular}{ccc}
\hline Lumpectomy & Number & Age $\left(x \pm s^{2}\right)$ \\
Mammectomy & 10 & $6.2 \pm 2.2$ \\
Regional mastectomy without involvement of cranial abdominal gland & 11 & $10.0 \pm 2.3$ \\
Regional mastectomy with involvement of cranial abdominal gland & 33 & $8.9 \pm 2.2$ \\
Radical mastectomy & 28 & $10.2 \pm 2.5$ \\
Total & 61 & $10.5 \pm 2.2$ \\
& 143 & $9.7 \pm 2.3$ \\
\hline
\end{tabular}

Table 4. Number of lesions and mean of distinct diagnoses on 143 dogs.

\begin{tabular}{lcc}
\hline & Number of patients & Mean of distinct diagnosis \\
\hline One lesion & 33 & 1.00 \\
Two lesions & 43 & 1.74 \\
Three lesions & 31 & 2.45 \\
Four lesions & 24 & 3.96 \\
Five lesions & 4 & 4.00 \\
Six lesions & 3 & 4.75 \\
Seven lesions & 4 & 6.00 \\
13 lesions & 1 & 143 \\
Total & & 2.14 \\
\hline
\end{tabular}

Table 5. Number and percentage of animals that developed new tumors by surgical technique.

\begin{tabular}{ccccc}
\hline & $\begin{array}{c}\text { Same } \\
\text { mammary gland }\end{array}$ & $\begin{array}{c}\text { Ipsilateral mammary } \\
\text { chain adjacent gland }\end{array}$ & $\begin{array}{c}\text { Ipsilateral mammary } \\
\text { chain non adjacent gland }\end{array}$ & $\begin{array}{c}\text { Contralateral } \\
\text { mammary chain }\end{array}$ \\
\hline Lumpectomy & $4(40 \%)$ & $2(20 \%)$ & $1(10 \%)$ & $3(30 \%)$ \\
Mammectomy & - & $0(0 \%)$ & $2(18.2 \%)$ & $2(18.2 \%)$ \\
$\begin{array}{c}\text { Regional mastectomy without } \\
\text { involvement of cranial abdominal gland } \\
\text { Regional mastectomy with involvement } \\
\text { of cranial abdominal gland } \\
\text { Radical mastectomy }\end{array}$ & - & $2(6.1 \%)$ & $4(12.2 \%)$ & $5(15.2 \%)$ \\
\hline
\end{tabular}

None of the patients submitted to lumpectomy and mammectomy died due to the disease or developed signs of the disease during follow-up. It was observed greater survival $(p<0.03)$ and disease free interval $(p<0.05)$ in patients of groups P1 and P2, when compared with P5, as shown in Figure 1 and Figure 2, respectively. New lesion development interval (Figure 3) was random and there was no evidence of reducing the interval of development of new lesions by using of a more extensive surgical technique $(p>0.05)$.

\section{Discussion}

The mean age of dogs diagnosed with mammary tumors and the search for veterinary assistance were in accordance with earlier reports [4] [18]-[20]. The high incidence of crossbreeds, Poodles and Cocker spaniels may be related to population profile. However, in a study by Zatloukal et al. (2005) [20], of 214 dogs, Poodles and Cocker spaniels had a statistically significant higher relative risk of developing mammary gland neoplasms. 


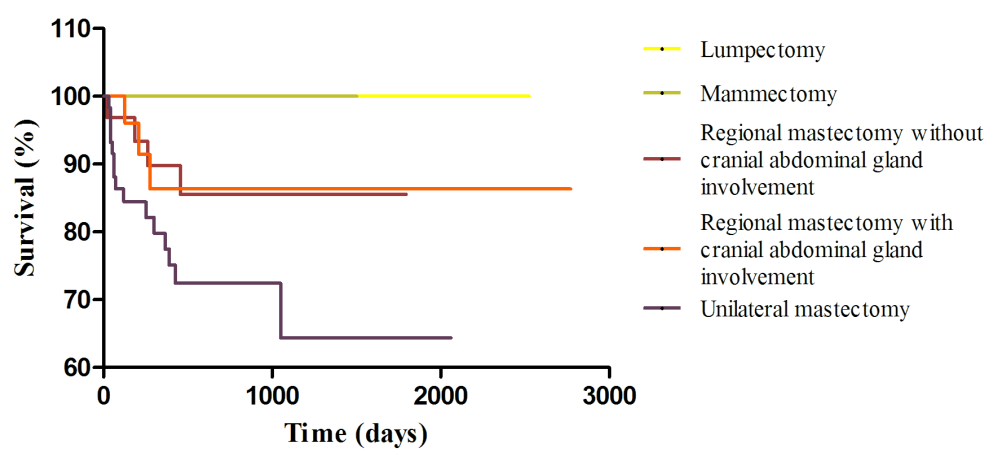

Figure 1. Graphical representation (Kaplan-Meier curve) of survival evaluation of 143 dogs with mammary tumors, by surgical technique.

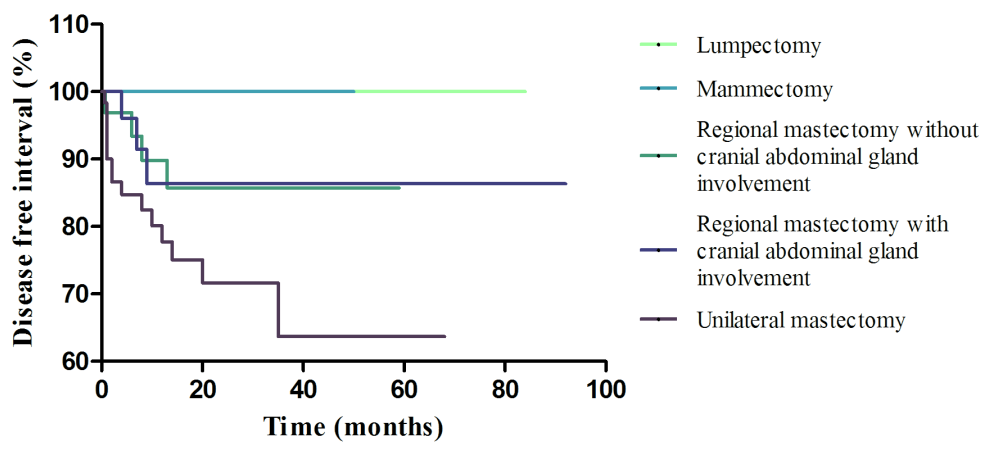

Figure 2. Graphical representation (Kaplan-Meier curve) of disease free interval evaluation of 143 dogs with mammary tumors, by surgical technique.

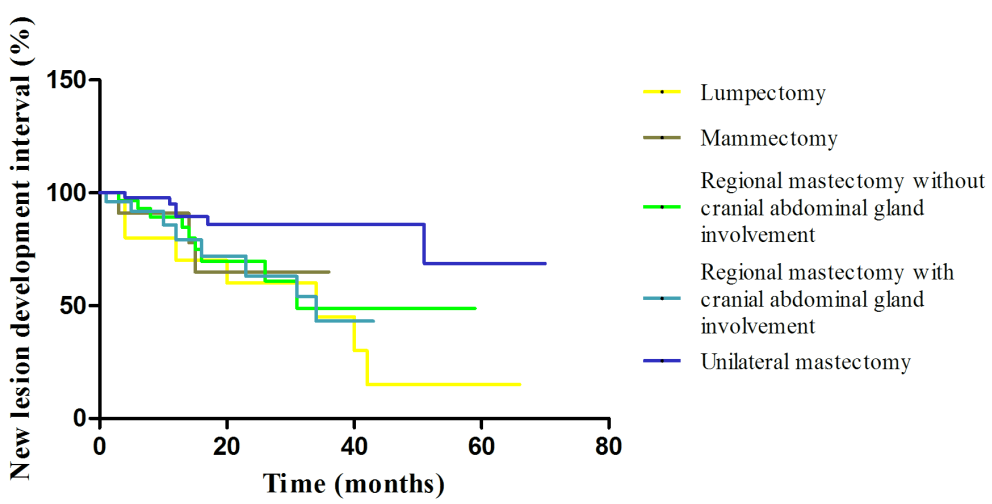

Figure 3. Graphical representation (Kaplan-Meier curve) of new lesion development interval evaluation of 143 dogs with mammary tumors, by surgical technique.

Multiple mammary tumors, seen in $84.6 \%$ of animals in this study, are not related with the possibility of multicentric disease and do not imply a worse prognosis [4]. Fowler et al. (1974) [21] and Benjamin et al. (1999) [22] described multiple lesions in over $60 \%$ of the cases, and each tumor should be examined separately, because there is a great possibility of distinct histopathological diagnoses. The strong correlation between number of lesions and distinct diagnoses, which occurred in $83.3 \%$ of the study population, is in accordance with Fowler et al. (1974) [21] and Cassali et al. (2011) [6].

In this study, malignant neoplasm frequency of $56 \%$ was superior to the $50 \%$ ratio reported by Sorenmo (2003) [4] and Sorenmo et al. (2013) [5]. However, De Nardi et al. (2002) [19] and Filho et al. (2010) [23], reported malignancy ratios of $68.4 \%$ and $73.3 \%$, respectively. These differences may be related to regional characteristics as contraceptive use [19] and delay in the search for veterinary assistance. In this study, benign 
mixed tumor was the most frequent benign neoplasm (56.2\%), but it was the second most frequently diagnosed (40\%) by Filho et al. (2010) [23]. Likewise, carcinoma in mixed tumor represented $47.5 \%$ of malignant neoplasms in this study, and $20.5 \%$ on the study by Filho et al. (2010) [23]. Frequencies reported in this study for each histological type differ from international literature reports [2] [15] [16], probably due to a lack of histological standardization for canine mammary tumors [24].

Surgical technique, performed as proposed by Brodey et al. (1983) [16] and Sorenmo et al. (2013) [5], was related to patient staging in $40.9 \%$ of the population in this study. There was a correlation between staging and patient age in $24.7 \%$ of cases, which implied the need for more aggressive surgery on older animals. World Health Organization (WHO) stage III, IV or V in older patients may be related to interval between tumor development and veterinary assistance, leading to the need of more aggressive procedures in these animals [25]. Gilbertson et al. (1983) [15] reported that some mammary lesions are associated with a higher risk for the development of invasive malignant neoplasms. Cassali et al. (2011) [6], reported alterations on the mammary epithelium molecular expression pattern suggesting intraepithelial and intraductal lesions, as the ones reported in this study, which may represent pre-neoplastic lesions and a premature level of canine breast cancer development, and substantiates premature and simpler surgical procedures.

Unlike the report by Stratmann et al. (2008) [2], there was no significant difference in ipsilateral and contralateral tumor development between surgical techniques, probably because, in this study, surgical technique was not randomly chosen, but based on macroscopic disease and clinical features. In addition, there was no correlation between subsequent lesions, probably due to a more detailed histopathological evaluation of each lesion.

Survival and disease free interval estimates were higher for dogs submitted to lumpectomy or mammectomy. This result may be related to early staging of these patients, which has better prognostic factors.

As MacEwen et al. (1985) [17] reported for dogs and Fisher (1977) [10] for women, surgical technique must be chosen based on prognostic factors described on literature and there is no benefit on overall survival, disease free interval and new lesion development interval in dogs treated randomly by radical mastectomy [5]. The effectiveness of a surgical treatment depends on the surgeon's overall understanding of the overall health of the patient, type and stage of cancer, adjuvant therapies available and expected prognosis [26].

\section{Conclusion}

Therefore, we conclude that surgical technique does not influence overall survival, disease free interval and new lesion development interval. Nevertheless, oncological surgery principles and established prognostic factors must be respected; patients must have routine checkups and, any lesion, however small, must be prematurely removed by surgery and; canine mammary tumors must be removed by the simplest procedure, with the goal of removing the entire lesion and the main lymphatic connections.

\section{Funding}

This article was developed at the Federal University of Minas Gerais on the year 2012 and was financed by the National Counsel of Technological and Scientific Development.

\section{References}

[1] Johnson, S.D. (1993) Reproductive Systems. In: Slatter, D., Ed., Textbook of Small Animal Surgery, 2nd Edition, Saunders Company, Philadelphia, 2177-2192.

[2] Stratmann, N., Failing, K., Richter, A. and Wehrend, A. (2008) Mammary Tumor Recurrence in Bitches after Regional Mastectomy. Veterinary Surgery, 37, 82-86. http://dx.doi.org/10.1111/j.1532-950X.2007.00351.x

[3] Mohammed, R.A.A., Martin, S.G., Mahmmod, A.M., Macmillan, R.D., Green, A.R., Paish, E.C. and Ellis, I.O. (2011) Objective Assessment of Lymphatic and Blood Vascular Invasion in Lymph Node-Negative Breast Carcinoma: Findings from a Large Case Series with Long-Term Follow-Up. Journal of Pathology, 223, 358-365. http://dx.doi.org/10.1002/path.2810

[4] Sorenmo, K. (2003) Canine Mammary Gland Tumors. Veterinary Clinics of North America: Small Animal Practice, 33, 573-596. http://dx.doi.org/10.1016/S0195-5616(03)00020-2

[5] Sorenmo, K.U., Worley, D.R. and Goldschmidt, M.H. (2013) Tumors of the Mammary Gland. In: Withrow, S.J., Vail, D.M. and Page, R.P., Eds., Withrow and MacEwen's Small Animal Clinical Oncology, 5th Edition, Saunders Company, Philadelphia, 538-556. http://dx.doi.org/10.1016/B978-1-4377-2362-5.00027-X 
[6] Cassali, G.D., Lavalle, G.E., De Nardi, A.B., Ferreira, E., Bertagnolli, A.C., Estrela-Lima, A., et al. (2011) Consensus for the Diagnosis, Prognosis and Treatment of Canine Mammary Tumors. Brazilian Journal of Veterinary Pathology, 4, 153-180.

[7] Patsikas, M.N. and Dessiris, A. (2006) The Lymph Drainage of the Neoplastic Mammary Glands in the Bitch: A Lymphographic Study. Anatomy Histology and Embryology, 35, 228-234. http://dx.doi.org/10.1111/j.1439-0264.2005.00664.x

[8] Pereira, C.T., Rahal, S.C., De Carvalho Balieiro, J.C. and Ribeiro, A.A. (2003) Lymphatic Drainage on Healthy and Neoplastic Mammary Glands in Female Dogs: Can It Be Really Altered? Anatomy Histology and Embryology, 32, 282-290. http://dx.doi.org/10.1046/j.1439-0264.2003.00485.x

[9] Hedlund, C.S. (2008) Cirurgia dos Sistemas Reprodutivo e Genital. In: Fossum, T.W., Hedlund, C.S., Johnson, A.L., Schulz, K.S., Seim, H.B., Willard, M.D., Bahr, A. and Carrol, G.L., Eds., Cirurgia de Pequenos Animais, 3th Edition, Elsevier, Rio de Janeiro, 702-774.

[10] Fisher, B., Montague, E., Redmond, C., Barton, B., Borland, D., Fisher, E.R., et al. (1977) Comparison of Radical Mastectomy with Alternative Treatments for Primary Breast Cancer. A First Report of Results from a Prospective Randomized Clinical Trial. Cancer, 39, 2827-2839. http://dx.doi.org/10.1002/1097-0142(197706)39:6<2827::AID-CNCR2820390671>3.0.CO;2-I

[11] Bland, C.S. (1981) The Halsted Mastectomy: Present Illness and Past History. The Western Journal of Medicine, 134, 549-555.

[12] Fergunson, R.H. (1985) Canine Mammary Gland Tumors. Veterinary Clinics of North America: Small Animal Practice, 15, 501-511.

[13] Olson J.S. (2005) Bathsheba’s Breast: Women, Cancer \& History. 1st Edition, John Hopkins University Press, Baltimore, $302 \mathrm{p}$.

[14] Cotlar, A.M., Dubose, J.J. and Rose, D.M. (2003) History of Surgery for Breast Cancer: Radical to Sublime. Current Surgery, 60, 329-337. http://dx.doi.org/10.1016/S0149-7944(02)00777-8

[15] Gilbertson, S.R., Kurzman, I.D., Zachrau, R.E., Hurvitz, A.I. and Black, M.M. (1983) Canine Mammary Epithelial Neoplasms: Biological Implications of Morphologic Characteristics Assessed in 232 Dogs. Veterinary Patholgy, 20, 127-142.

[16] Brodey, R.S., Goldschmidt, M.H. and Roszel, J.R. (1983) Canine Mammary Gland Neoplasms. Journal of American Animal Hospital Association, 19, 61-90.

[17] MacEwen, E.G., Harvey, H.J., Patnaik, A.K., Mooney, S., Hayes, A., Kurzman, I. and Hardy Jr., W.D. (1985) Evaluation of the Effect of Levamizole and Surgery on Canine Mammary Cancer. Journal of Biological Response Modifiers, 4, 418-426.

[18] Daleck, C.R., Franceschini, P.H., Alessi, A.C., Santana, A.E. and Martins, M.I.M. (1998) Aspectos Clínico e Cirúrgicos do Tumor Mamário Canino. Ciência Rural, 28, 95-100. http://dx.doi.org/10.1590/S0103-84781998000100016

[19] De Nardi, A.B., Rodaski, S., Souza, R.S., Costa, T.A., Macedo, T.R., Rodigheri, S.M., Rios, A. and Piekarz, C.H. (2002) Prevalência de Neoplasias e Modalidades de Tratamentos em Cães Atendidos no Hospital Veterinário da Universidade Federal do Paraná. Archives of Veterinay Science, 7, 15-26.

[20] Zatloukal, J., Lorenzova, J., Tichy, F., Necas, A., Kecova, H. and Kohout, P. (2005) Breed and Age Risk Factors for Canine Mammary Tumours. Acta Veterinaria Brno, 74, 103-109. http://dx.doi.org/10.2754/avb200574010103

[21] Fowler, E.H., Wilson, G.P. and Koester, A. (1974) Biologic Behavior of Canine Mammary Neoplasms Based on a Histogenic Classification. Veterinay Pathology, 11, 212-229. http://dx.doi.org/10.1177/030098587401100303

[22] Benjamin, S.A., Lee, A.C. and Saunders, W.J. (1999) Classification and Behavior of Canine Epithelial Neoplasms Based on Life-Span Observations in Beagles. Veterinary Pathology, 36, 423-436. http://dx.doi.org/10.1354/vp.36-5-423

[23] Filho, J.C., Kommers, G.D., Masuda, E.K., Marques, B.M.F.P.P., Fighera, R.A., Irigoyen, L.F. and Barros, C.S.L. (2010) Estudo Retrospectivo de 1647 Tumores Mamários em Cães. Pesquisa Veterinária Brasileira, 30, 177-185. http://dx.doi.org/10.1590/S0100-736X2010000200014

[24] Salgado, B.S. and Cassali, G.D. (2012) Perspectives for Improved and More Accurate Classification of Canine Mammary Gland Neoplasms. Veterinary Pathology Online, 0, 1-2.

[25] Campos, C.B., Horta, R.S., Cobucci, G.C., Botelho, F.P.R., Lavalle, G.E. and Cassali, G.D. (2012) Abordagem Cirúrgica das Neoplasias Mamárias em Pequenos Animais: Perfil do Paciente, Comportamento e Epidemiologia Tumoral. Veterinária e Zootecnia (Suplemento), 18, 7-1.

[26] Fisher, B. (2008) Biological Research in the Evolution of Cancer Surgery: A Personal Perspective. Cancer Research, 68, 10007-10020. http://dx.doi.org/10.1158/0008-5472.CAN-08-0186 